\title{
THE ELASTIC MODULUS AND ELASTIC LIMIT OF RUBBER AND THEIR RELATION TO CHANGE OF TEMPERATURE.
}

By J. C. Shedd and R. L. Ingersol.

HE fact that a loaded rubber tube will shorten when steam is passed through it has long been a striking experiment; it has also proven a somewhat puzzling one.

The first explanation suggested was that of a negative coefficient of expansion. Direct experiment upon short solid pieces of rubber have failed to support this view. Under all conditions the volumetric coefficient has been found to be positive. ${ }^{1}$ A. E. Lundal ${ }^{2}$ found the cubical coefficient to be positive and very large; also to increase rapidly with rise of temperature. He also confirmed the previous conclusion of $\mathrm{W}$. Röntgen that the volumetric change due to stretching is very small. Further he found that the cubical coefficient of stretched rubber is identical with that of rubber not under stress. The linear coefficient of expansion as determined in the experiments above noted was found to be positive for rubber not under stress, but for rubber under stress seemed to be abnormal, now positive, now negative, and always dependent upon the stress. Lundel concludes : (I.) The temperature coefficient of linear expansion is positive for small values of the stretching force, but decreases and becomes negative as this force increases. (II.) That this coefficient increases rapidly with rise of temperature, is negative for low values of stretching force but positive for higher values. There is therefore an inversion temperature where the coefficient is zero, also this inversion temperature is higher as the stretching force increases. A review of these experiments leads one to conclude that the

${ }^{1}$ P. Joule, J. Pierre and P. Lebedeff; A. Winkelmann, Handbuch d. Physik, 2, p. $66, \mathrm{I} 896$.

2 Wiedemann Annalen, Dec., I898, p. 74I. 
A second explanation was advanced by G. Schmulervitsch. ${ }^{1} \mathrm{He}$ suggested that the linear coefficient like the cubical is always positive, but that a rise of temperature increases the elastic modulus. G. R. Dallander went further and gave an equation for the relation of the elastic modulus and the temperature. ${ }^{2}$ Lundal ${ }^{3}$ confirmed the equation of Dallander, finding an increase of about I I per cent. between $0^{\circ} \mathrm{C}$. and $60^{\circ} \mathrm{C}$. $\mathrm{He}$ also found that the increase is smaller when the stretching force is increased. In arriving at this conclusion Lundal introduces no correction for the temperature dilatation of the rubber, and he significantly remarks in this connection that "it is strictly speaking uncertain whether the elastic modulus increases or decreases with rises of temperature." In the experiments for determining the elastic modulus a peculiar source of error is present which Lundal calls the "elastic-after-effect" (Nachwirkung). This seems to be somewhat of the nature of viscosity and is found to diminish as the temperature rises. According to Lundal this diminution goes on up to $50^{\circ} \mathrm{C}$. and then increases. $\mathrm{He}$ does not, however, give much weight to his determination above $60^{\circ} \mathrm{C}$.

The purpose of the present experiments was to extend the stretching force over a much greater range than heretofore and to study the elastic-after-effect. The first apparatus used was a simple hook support for one end of a common rubber band, with a weight-pan mounted at the other end. For load increments stamped rifle bullets were used which were found to be remarkably uniform in mass and of approximately Io grams mass each. The elongation was read with a cathetometer. A large number of readings were taken upon a single rubber band at room temperature; from 10 to Ioo grams being used as load increments. Also various loads were placed on the weight pan and left for a number of hours or days and the readings then taken for both rising and falling loads. The following conclusions were reached:

I. The same rising curves are traced whether the interval be one half minute, one minute or two minutes. The falling curves approximately coincide.

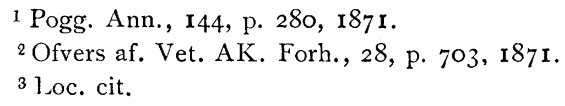


behavior of rubber cannot be adequately explained on the supposition of a negative cubical or linear coefficient of expansion.

2. The return curve is never the same as the rising curve even for a small load range.

3. Hence the "elastic-after-effect" or viscosity factor cannot be eliminated by merely making an extra time allowance while taking the readings.

4. If the load exceed a certain limit the same cycle cannot be repeated, i. e., the rubber seems to receive a permanent set.

In order to vary the temperature the following simple scheme was used: A stream of water from the faucet $F$ (Fig. I) was passed through a glass tube bent back and forth and under which was placed a gas flame. The water after being heated was passed through the chamber $c$ which surrounded the inner chamber $d$. By controlling the volume of water the temperature of the chamber $d$ could be regulated quite closely. The range of temperature available was from $\mathrm{II}^{\circ} \mathrm{C}$. to $93^{\circ} \mathrm{C}$. (the boiling point at this altitude being $94^{\circ} \mathrm{C}$.) A large number of curves were obtained at different tem-

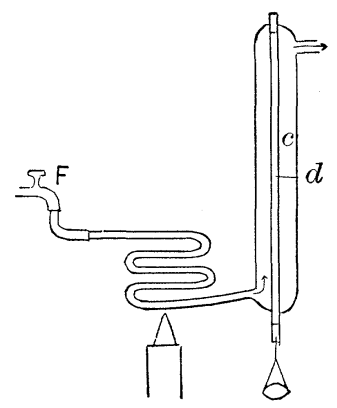

Fig. 1. peratures and with different load limits; also different load increments were used as well as initial loads of various values, which were left on the weight pan for longer or shorter periods. In all of this work the conclusions already given were confirmed to the fullest extent.

It was next thought worth while to try to eliminate the per saltem feature of the method of loading and unloading. This was done by mounting a Mariotte flask in such a way as to give a constant flow of water into a beaker which replaced the weight pan. A steady discharge rate was secured by mounting a siphon on a cork which floated within the beaker. Readings were taken at minute intervals both rising and falling curves being secured. The results thus obtained showed that the curves gotten by the two methods do not materially differ. The easier method of fixed load increments was therefore again adopted. 
The Elastic Modulus.

It was now apparent that the load limit above which a given cycle could not be repeated with a given specimen is very small. Data therefore obtained from the same specimen at different tem-

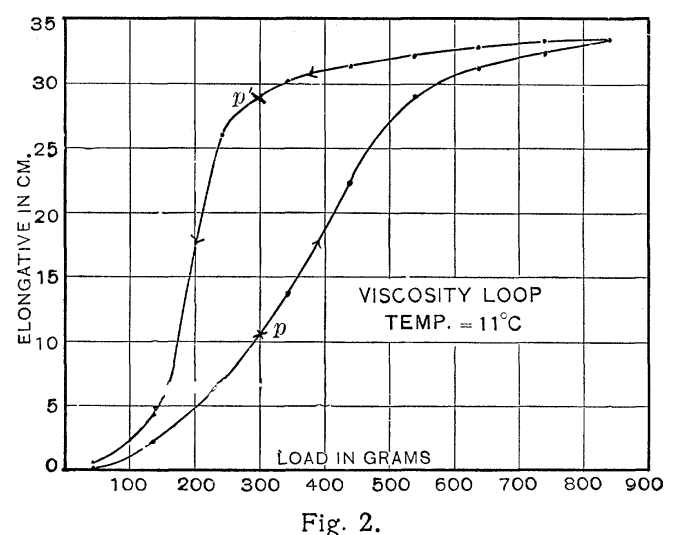

peratures and for different load limits would not be strictly comparable and hence of no great value. It was also apparent that it

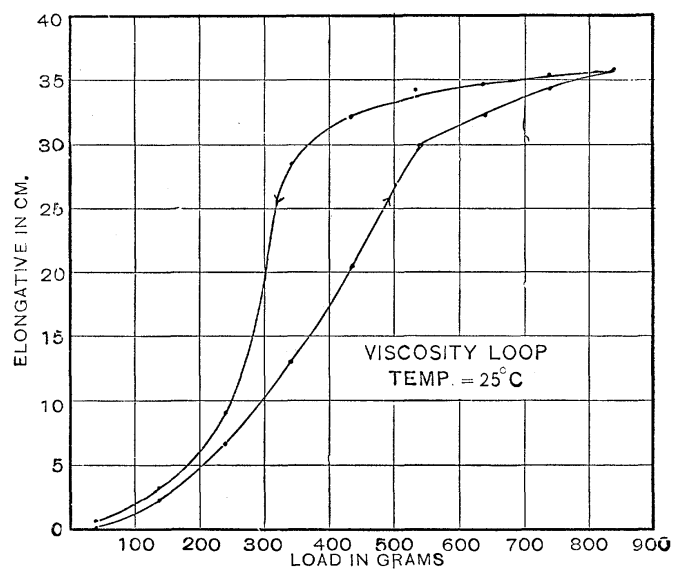

Fig. 3.

would be practicably impossible to obtain a number of single rubbers exactly alike. A number of rubbers were therefore tested by means of a small load and their relative cross-sections determined. 
Combinations of rubbers were then made which were regarded as of the same cross-section. Care was also taken that the load limit should be low enough so that the rising and falling curves should be as nearly as possible parallel.

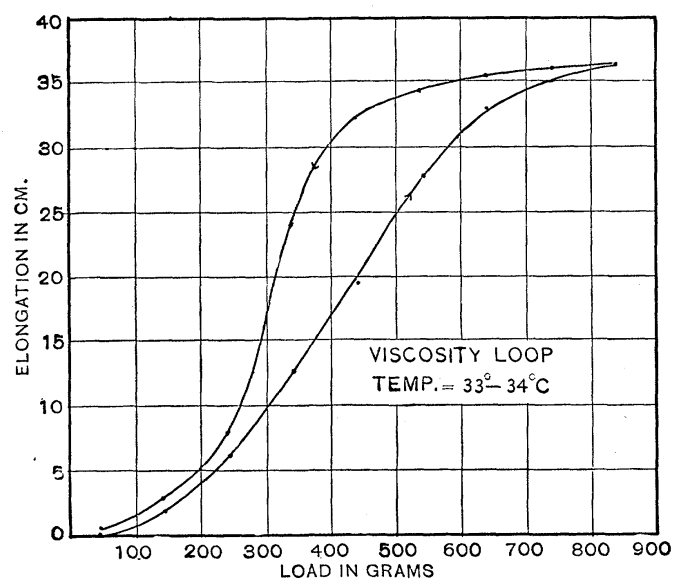

Fig. 4.

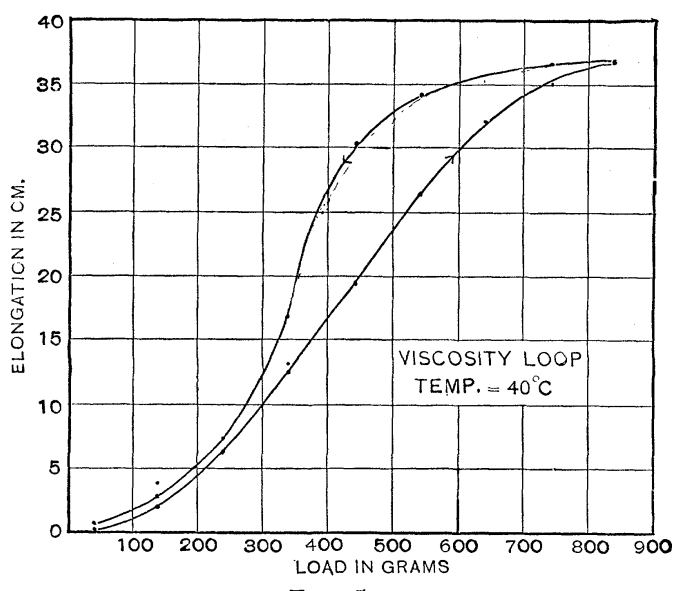

Fig. 5.

To the conclusions already noted may now be added those stated below. In reaching these conclusions the slope of the load-elongation curve is regarded as a function of the elastic modulus (see Figs. 2-8).

5. The value of $E$ depends not alone upon the temperature but also upon the load. 
6. For a given load the value of $E$ seems to increase slightly with increase of temperature.

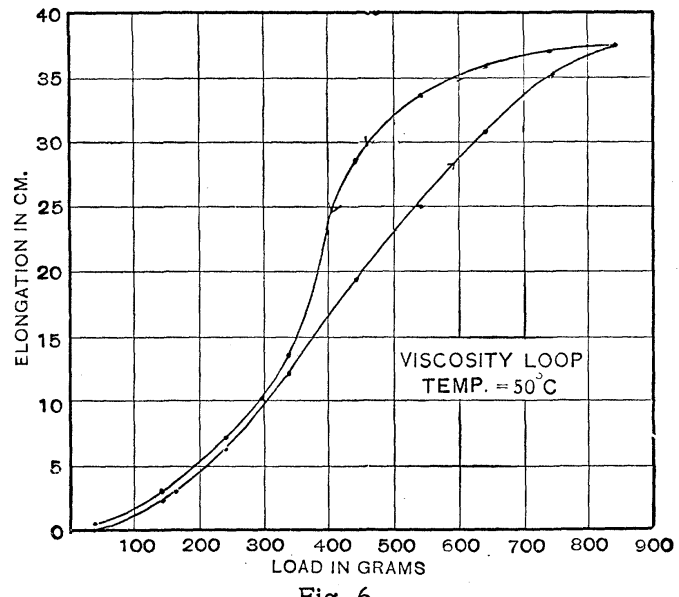

Fig. 6.

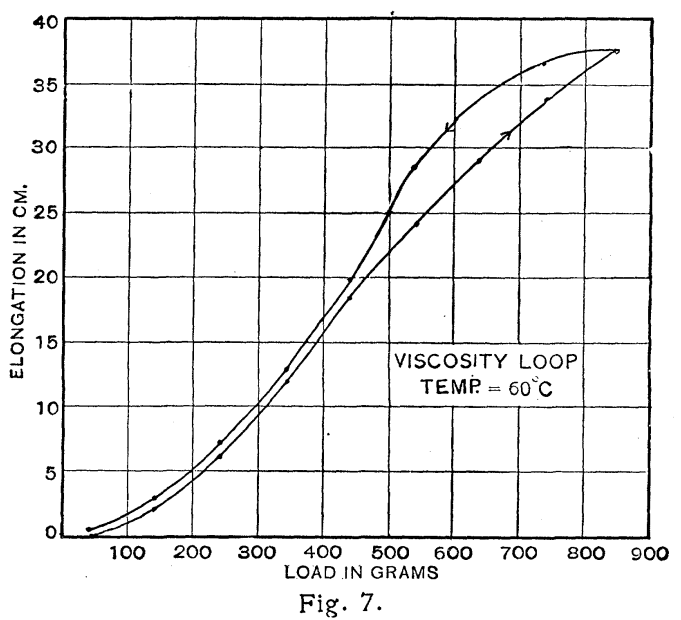

7. For a given temperature the value of $E$, beginning with zero load, slowly diminishes, then remains constant for a considerable range and finally sharply increases in value. The first stage would seem to correspond to initial viscosity or static friction and the last to a permanent set. In the falling load the third stage is prolonged at the expense of the second.

8. In case the third stage is not entered upon the return curve is more nearly parallel to the rising curve. 
Energy Absorbed Due to Viscosity. - The fact that rising and falling curves never coincide must be due to the irreversible action of viscosity. It is also apparent that the area of the curve, like that of the hysteresis loop, is a function of the energy absorbed. If

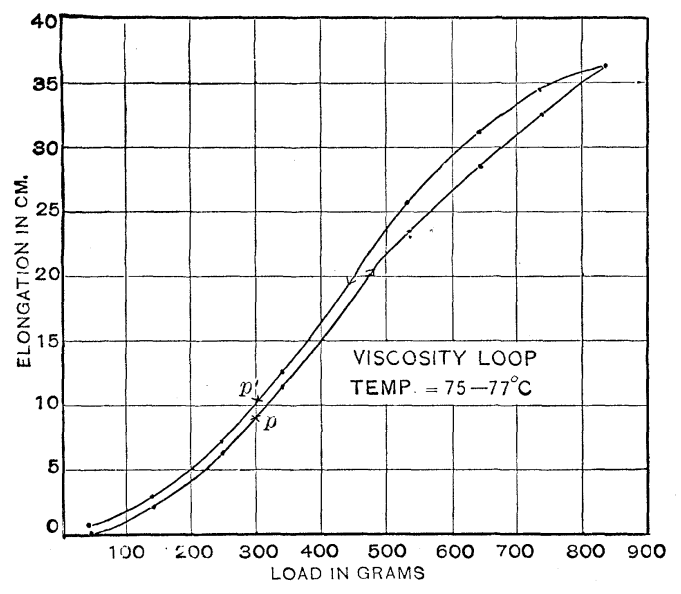

Fig. 8.

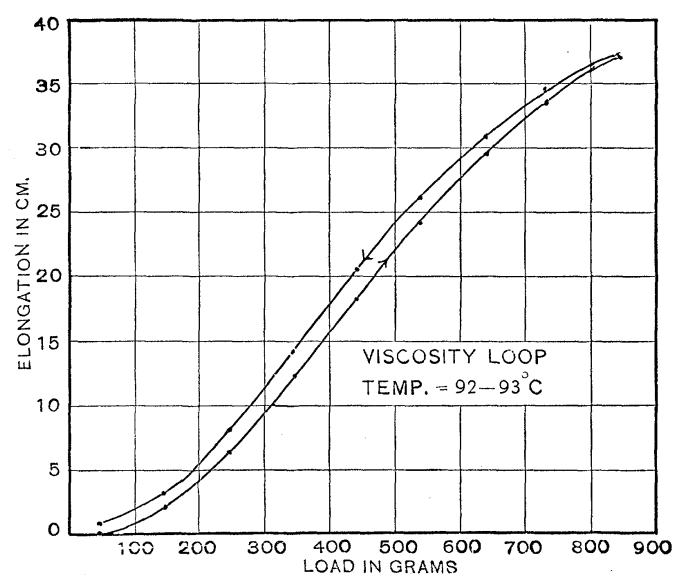

Fig. 9.

then we compare the loops having the same range of load but taken at different temperatures we shall be able to compare the viscosities at these temperatures. Two series of such comparative areas are given in the following table: 


\begin{tabular}{ccc}
\multicolumn{3}{c}{ Series I, Load limit $84^{\circ}$ grams. } \\
Energy Absorbed per & Temp. & Energy Absorbed per \\
Cycle (comparative). & C. & Cycle (comparative). \\
662 & $50^{\circ}$ & 338 \\
475 & $60^{\circ}$ & 179 \\
449 & $76^{\circ}$ & 129 \\
377 & $92^{\circ}$ & 145
\end{tabular}

\begin{tabular}{cc}
\multicolumn{3}{c}{ Series II, Load limit ro8o grams. } \\
Temp. & Energy Absorbed per Cycle. \\
$18^{\circ}$ & 842 \\
$29^{\circ}$ & 535 \\
$36^{\circ}$ & 488 \\
$85^{\circ}$ & 152
\end{tabular}

The plat of these tables (Fig. 9) would lead to the conclusion that:

9. The energy dissipated per cycle due to viscosity depends upon the load limit, falls rapidly with rise of temperature, and becomes asymptotic to a fixed value.

\section{Elastic Limit.}

A study of the viscosity loops would seems to make two definitions of the elastic limit possible. In the first place on the rising curve there is seen to be a more or less well defined "knee" where the relation of stress to strain undergoes a marked change. This "knee" might be said to mark the elastic limit. The elastic limit so defined is found to rise as the temperature rises.

In the second place it is probable that a more comprehensive definition would be had by considering the descending curve also. The elastic limit would then be defined as that point above which the ascending and descending curves are no longer parallel. This point lies much lower down on the curve than does the first mentioned point, and it also rises as the temperature rises and at a somewhat faster rate. This second definition of the elastic limit could be given as follows: The elastic limit is the limiting value of the stress (or strain) for which the body upon being released will repeat its previous history in exactly reversed order.

This definition is more comprehensive in that it says that the history must be repeated in reversed order and not merely that the body must return to its original state.

We may now add to the previous conclusions the following: IO. The viscosity of rubber is relatively large at low tempera- 
tures, falls rapidly as the temperatures rises, and reaches an approximately constant value at about $80^{\circ} \mathrm{C}$.

II. The elastic limit of rubber rises with rise of temperature.

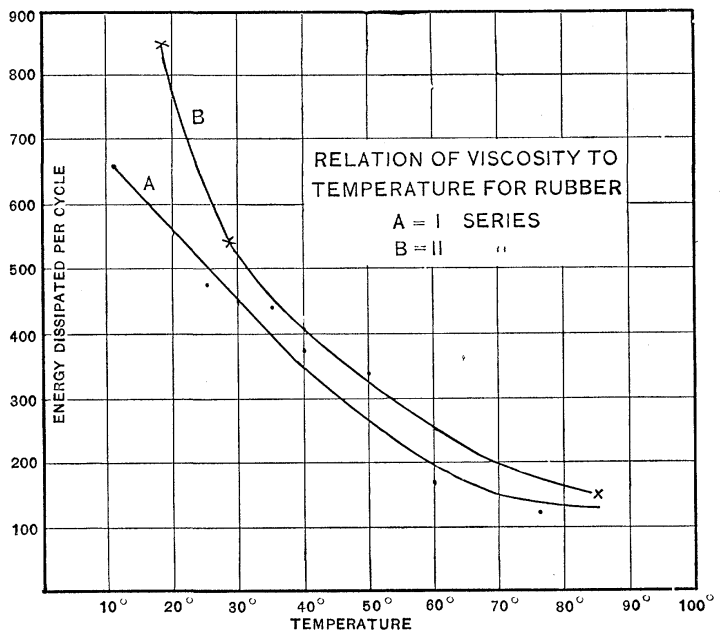

Fig. 10.

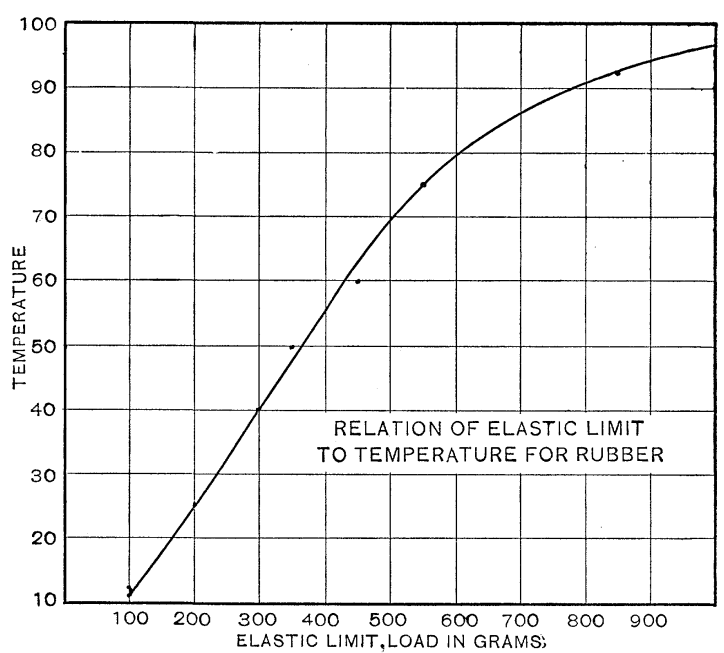

Fig. 11.

The fact that the viscosity loop approached a constant area would indicate that the rise of the elastic limit is indefinite, limited only by 
the change of state of the rubber from a viscous solid to a viscous fluid (see plat IO).

A consideration of the viscosity loop affords a partial explanation of the behavior of the rubber tube spoken of at the beginning of this paper. Let us suppose that the temperature is $\mathrm{I} \mathrm{I}^{\circ} \mathrm{C}$., and that the load is 300 grams as shown on Fig. 2. On the rising curve this would be represented by the point $p$. However, if by chance, the rubber has been so handled as to have passed around the cycle then the point $p^{\prime}$ might more nearly represent the state of the rubber. Now if the temperature be raised to $75^{\circ} \mathrm{C}$., points $p$ and $p^{\prime}$ on Fig. 8 would approximately represent the state of the rubber. In the latter case the contraction would be $17 \mathrm{~cm}$. as against $1.75 \mathrm{~cm}$. in the former case, and would be due, not so much to an increase in the elastic modulus, as to a rise in the elastic limit.

\section{Summary.}

We may conclude by dividing the history of a cycle into the following parts :

A. The first part of the curve has a small slope showing an apparently high value for $E$. This in a measure corresponds to the early stage of the magnetization curve of iron.

$B$. The second stage shows a comparatively constant but smaller value of $E$.

$C$. In the third stage the curve bends sharply showing a very high value for $E$. During this stage the rubber is in an abnormal state behaving very much like a metallic wire. This stage ends abruptly by the breaking of the rubber, or else the rubber receives a permanent set as is shown by the descending curve. As the temperature rises stage $B$ is extended in both directions $D$. The form of the descending curve will depend upon whether or not stage " $\mathrm{C}$ " has been reached.

In conclusion it is apparent that all experimental work upon rubber should be conducted upon that part of stage $B$ which lies below the elastic limit as defined in the second instance above. Also that the previous history of the specimen under test should be known.

Physical Laboratory, Colorado College, April, 1904. 